NBER WORKING PAPER SERIES

\title{
ENVIRONMENTAL INVESTMENT AND POLICY WITH DISTORTIONARY TAXES AND ENDOGENOUS GROWTH
}

\author{
Don Fullerton \\ Seung-Rae Kim \\ Working Paper 12070 \\ http://www.nber.org/papers/w12070 \\ NATIONAL BUREAU OF ECONOMIC RESEARCH \\ 1050 Massachusetts Avenue \\ Cambridge, MA 02138 \\ March 2006
}

\begin{abstract}
We are grateful for financial support to the first author from Japan's Economic and Social Research Institute (ESRI), and to the second author from the Joseph L. Fisher Dissertation Fellowship of Resources for the Future (RFF). We are also grateful for comments on earlier drafts from David Bradford, David Kendrick, Sjak Smulders, Pete Wilcoxen, Rob Williams, and Anastasios Xepapadeas. This paper is part of the NBER's research program in Public Economics. The views expressed herein are those of the author(s) and do not necessarily reflect the views of the National Bureau of Economic Research.

(C2006 by Don Fullerton and Seung-Rae Kim. All rights reserved. Short sections of text, not to exceed two paragraphs, may be quoted without explicit permission provided that full credit, including $\odot$ notice, is given to the source.
\end{abstract}


Environmental Investment and Policy with Distortionary Taxes and Endogenous Growth Don Fullerton and Seung-Rae Kim

NBER Working Paper No. 12070

March 2006

JEL No. O41, Q20, H41, H23

\begin{abstract}
$\underline{\text { ABSTRACT }}$
Recent studies consider public R\&D spending that affects abatement knowledge and endogenous growth, distortionary taxes that affect physical and human capital formation, pollution taxes that affect environmental degradation, and regeneration that restores natural capital. Our model combines all of those elements. We show how the combination affects results from each prior model, focusing on two parameters that represent the need for distorting taxes, and the productivity of abatement knowledge relative to pollution. First, either of these two extensions can reverse the prior finding that pollution tax revenue is more than enough to pay for public abatement R\&D. Second, tax distortions and externalities substantially alter prior findings that the ratio of public to private capital is based only on output elasticities. Third, our dynamic model affects prior static findings about how other public spending "crowds out" provision of the environmental public good. Fourth, we show whether a greater need for public spending leads to greater increases in the distorting tax or pollution tax. Fifth, while prior research is optimistic that environmental regulation can boost economic growth, we show how it may increase or decrease the growth rate - even if it raises welfare.
\end{abstract}

\author{
Don Fullerton \\ Department of Economics \\ University of Texas at Austin \\ Austin, TX 78712 \\ and NBER \\ dfullert@eco.utexas.edu \\ Seung-Rae Kim \\ Korea Institute of Public Finance \\ 79-6 Garak-Dong Songpa-Gu \\ Seoul, 138-774, Korea \\ srkim@kipf.re.kr
}


To ensure that economic growth and environmental preservation are compatible and socially optimal, it is crucial to understand the simultaneous dynamic interactions among public spending needs, distortionary taxes, pollution taxes, abatement $\mathrm{R} \& \mathrm{D}$, technological progress, pollution externalities, ecological regeneration, private economic activities, welfare, and growth. How can environmental investment and tax policies contribute to the productivity of private factors of production and to sustainable economic growth? So far, existing research has used a number of different models to address different questions that each focus on a particular interaction among only some of the policies and outcomes just listed.

Existing endogenous growth models have physical capital, human capital, and fixed inputs such as raw labor, but environmental models add other inputs supplied by nature. Bovenberg and Smulders $(1995,1996)$ extend the model of Lucas (1988) by incorporating two stocks that are "public" inputs to production: the environment and abatement knowledge. ${ }^{1}$ They consider a pollution tax, but not other distorting taxes.

Bovenberg and de Mooij (1997) and Hettich (1998) consider both a pollution tax and a distorting tax on private income, but not those two "public" capital stocks. The former paper includes public infrastructure, and the latter has human capital, but neither considers the dynamics of investment in abatement or environmental quality. Yet these papers can ask what is the optimal tax mix, where the pollution tax affects externalities on production and the income tax affects private capital formation. ${ }^{2}$ They also ask whether a tightening of pollution standards can boost long run growth.

In this paper, we combine various elements from prior models to construct a single endogenous growth model that we then use to answer more of their questions in a way that is more complete and comparable than in prior papers. We show how the added features of our model change and in some cases reverse previous answers. We focus on five questions, first noting how prior papers address them.

\footnotetext{
${ }^{1}$ Other models with nature as an input to production include Tahvonen and Kuuluvainen (1991), Gradus and Smulders (1993), van Ewijk and van Wijnbergen (1995), Smulders and Gradus (1996), Elbasha and Roe (1996), Mohtadi (1996), Xepapadeas (1997), and Bovenverg and de Mooij (1997).

${ }^{2}$ An income tax distorts intertemporal choices. It leads in neoclassical growth models to a lower long run level of income and in endogenous growth models to a lower long-run growth rate. See Rebelo (1991), Rebelo and Stokey (1995), Jones et al (1993), and Jones and Manuelli (1997). Taxes on capital income or total income reduce the rate of saving and growth, while taxes on labor income or consumption have only level effects, not growth effects.
} 
As in Bovenberg and Smulders $(1995,1996)$, our model has three assets: private capital, accumulated either from physical investment or human capital formation; abatement knowledge, accumulated from public R\&D spending; and environmental quality, modeled as a stock of a renewable resource that is depleted by pollution but augmented by ecological regeneration. This natural capital stock provides a nonrival public input to production and nonrival benefits in utility, so pollution has negative external effects on both. Firms choose inputs of physical capital and "effective pollution", which is the product of actual pollution and public abatement knowledge. Thus, while some pollution is essential to production, it can be reduced either by public spending on abatement or by public policies to control emissions.

We extend Bovenberg and Smulders in two important ways, summarized by two additional parameters. First, we add a distortionary income tax that must be used to pay for government transfer spending that is a fixed fraction of private income, $\varphi .^{3}$ Second, we suppose that "effective pollution" is the product of abatement knowledge and actual pollution taken to the exponent $\varepsilon$, a parameter that allows for differential productivity of actual pollution relative to abatement knowledge. ${ }^{4}$ We show how either of these two generalizations can reverse their conclusions.

We use all of these model features together to derive some results analytically, and then to show seven nonlinear equations for seven important endogenous variables. These equations cannot be used to find closed form solutions, and so we show some other important results using numerical analysis for the case of global warming.

We are now in a position to describe the five major questions we address, the findings of prior models, and how our extensions affect the answers.

(1) Are pollution tax revenues always enough to pay for optimal public spending on abatement R\&D? Bovenberg and Smulders (1995) say "yes," using their model described above with private capital, abatement knowledge, and natural capital. Here, we show analytically that this conclusion can be reversed when a distorting income tax is needed to pay for transfers $(\varphi>0)$. It can also be reversed if effective pollution is

\footnotetext{
${ }^{3}$ Since Bovenberg and de Mooij (1997) and Hettich (1998) consider a both a distorting tax and a pollution tax with endogenous growth, we note that relative to their models, we add two dynamic considerations: abatement knowledge accumulates from R\&D spending, while natural capital is depleted by pollution and augmented by natural regeneration. We also address additional questions.

${ }^{4}$ Bovenberg and de Mooij (1997) consider effective pollution as current abatement spending times pollution to an exponent. We employ their idea but use the stock of abatement knowledge.
} 
augmented more by abatement than by actual pollution (where pollution has exponent $\varepsilon<1$ ). With either generalization, pollution tax revenue may fall short of optimal abatement spending, which then requires a higher distorting income tax.

(2) What is the optimal public capital relative to private capital? Barro (1990) and Barro and Sala-i-Martin (1992, 1995) consider public "infrastructure" and find that the answer is based on the ratio of pure output elasticities. This ratio is 0.315 using our parameters (where our public capital is "abatement knowledge" instead of "infrastructure"). Relative to their model we add tax distortions and pollution externalities, and we find that the optimal ratio almost doubles (to 0.619).

(3) Is government's provision of the environmental public good "crowded out" by the need to provide non-environmental public goods? Metcalf (2003) and Gaube (2005) ask this question in static models where a labor tax distorts labor supply, and they show conditions under which increased non-environmental spending will raise environmental quality. Relative to their models, we add the dynamics of endogenous growth and a tax on capital income. In our numerical model, all increases in required government spending necessitate increases to both the income tax and pollution tax, both of which reduce output and pollution. The result is more natural capital.

(4) Does greater need for public revenue mean larger increases in the income tax or pollution tax? This is not the well-researched "double dividend hypothesis", which is about tax reform. With endogenous growth, for example, Bovenberg and de Mooij (1997) and Hettich (1998) show effects of a revenue-neutral reform to raise the pollution tax and reduce the distorting tax. They look at non-optimal paths (since we already know effects on welfare of a change from the optimum!). Here, we look not at tax reforms but only at optimal growth paths. For all increases in required public spending, we find that both tax rates rise. The income tax rises relatively more than the pollution tax for initial increases in public spending, but subsequent spending hikes lead to greater relative increases in the pollution tax.

(5) When does an environmental tax raise economic growth, or welfare, or both? Environmental policy normally has costs in models with exogenous growth, but Bovenberg and Smulders $(1995,1996)$ and Hettich (1998) show how it can boost growth in models with endogenous growth. Here, we show how that optimistic view must be tempered by either of our two generalizations. With sufficient need for 
distortionary taxation ( $\varphi$ high enough) or with abatement more effective than actual pollution ( $\varepsilon$ low enough), then a higher pollution tax may reduce growth even while it raises welfare. We also show analytically the conditions under which it has the opposite effects, raising growth but reducing welfare.

The rest of this paper is organized as follows. Section 1 sets up the model and describes the balanced-growth equilibrium path. Section 2 discusses optimal corrective government policies in steady state, with some numerical applications, and it examines growth and welfare effects of a tighter environmental policy in a secondbest world. Section 3 contains some concluding remarks.

\section{The Model}

This section presents a simple model with endogenous determination of pollution and environmental quality as well as accumulation of private capital and pollution abatement knowledge. The economy produces a single final good. Individual household utility depends on consumption of the final good and on the quality of the environment. This environmental quality is a stock that acts as a nonrival consumption good but also as a public input to production.

The economy has three assets. The first is private capital, including both physical and human capital. The second is public abatement knowledge, a nonrival R\&D good. Either of these first two assets can be accumulated by devoting to it some fraction of output. ${ }^{5}$ The third asset is environmental quality, also called natural capital. It can be augmented only by reductions in pollution - either by reducing production or by investing in public abatement knowledge.

\subsection{Model Assumptions}

As in Tahvonen and Kuuluvainen (1991), the renewable natural resource, $N$, is “environmental quality," modeled as growing and depleting according to:

$$
\dot{N}=E(N)-P, \quad \text { where } \quad E^{\prime} \equiv \partial E / \partial N \lessgtr 0 \quad \text { and } \quad E^{\prime \prime} \equiv \partial^{2} E / \partial N^{2}<0,
$$

\footnotetext{
${ }^{5}$ We also solved a two-sector model in which one sector produces final goods and the other produces new abatement knowledge, but the extra sector adds complexity with no qualitative effect on results.
} 
where a dot over any variable represents the change over time. Environmental quality is augmented by $E(N)$, ecological growth through regeneration processes, and it is reduced by pollution, $P$, the extractive use of natural resources in production (e.g., using up clean air or water). As shown in Figure 1, regeneration $E(N)$ might initially increase with a larger $N$ (that is, $E^{\prime}>0$ ), but it eventually peaks and declines $\left(E^{\prime}<0\right)$ as the environment approaches its natural state [where $P=E(N)=0$ ]. Thus, natural capital accumulation features diminishing returns $\left(E^{\prime \prime}<0\right)$. On a sustainable steadystate path where $\dot{N}=0$, equation (1) implies that $P=E(N)$. Thus, $E(N)$ represents the absorption capacity of the environment. ${ }^{6}$

\section{Figure 1: Regeneration of the Environment}

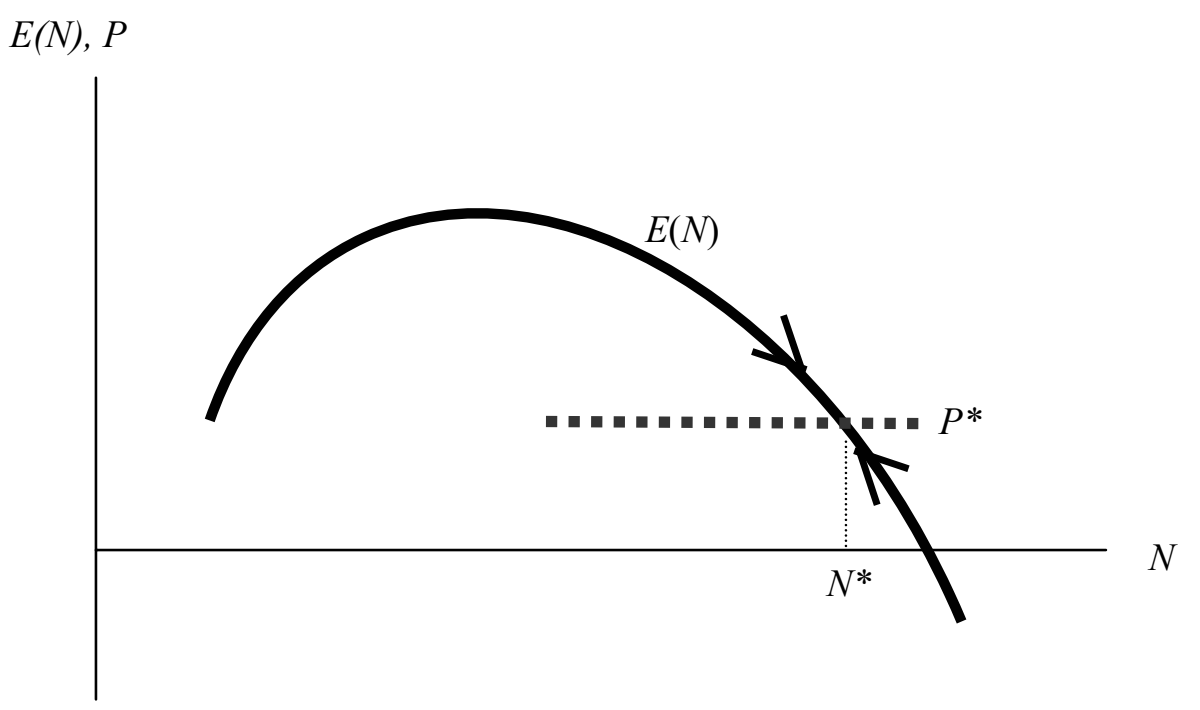

Besides the nonrival stock of natural capital $(N)$, the economy has a stock of nonrival knowledge about abatement $(H)$, and a private, rival stock of both physical

\footnotetext{
${ }^{6}$ 'Sustainable development' ( $\dot{N}=0$ ) requires that pollution $P$ is constant in the long run and does not exceed the maximum absorption capacity. Due to the concavity of $E(N)$, two levels of $N$ may have $\dot{N}=0$. One has low $N$ with $E^{\prime}>0$, and the other has high $N$ with $E^{\prime}<0$. With a constant level of pollution $P$, only the latter equilibrium is stable, so this study focuses on that case. For more details, see Neher (1990), Tahvonen and Kuuluvainen (1991), and Bovenberg and Smulders (1995, 1996).
} 
and other human capital $(K)$. Economic activity is described by a production function and uses of output:

$$
Y=A(N) F(K, Z)=C+\dot{K}+\delta_{K} K+q_{H} \dot{H}+q_{H} \delta_{H} H,
$$

where

$$
Z \equiv H P^{\varepsilon} \text {. }
$$

Production depends on $A(N)$, the positive 'production externality' from the natural environment. Cleaner air or water may improve health and productivity of workers, just as climate change may affect crop yields. Then $F()$ exhibits constant returns with respect to the two rival inputs ( $K$ and $Z$, discussed shortly). ${ }^{7}$ Production is nondecreasing in all arguments together. It exhibits diminishing returns with respect to each factor alone, while all inputs are essential. ${ }^{8}$ Eq. (2a) also shows the overall resource constraint of the economy. This single sector produces a flow of final output that can be consumed $(C)$, invested in new private capital $(\dot{K})$, used by government to generate new public knowledge about pollution abatement techniques $(\dot{H})$, or used for reinvestment to offset depreciation of the two man-made capital stocks $\left(\delta_{K} K+\right.$ $\left.q_{H} \delta_{H} H\right)$. Here, $q_{H}$ denotes the shadow price of abatement knowledge relative to private capital (i.e., the price at which the output of R\&D could be sold).

In eq. (2b), $Z$ is "effective pollution," an input that can be provided either by actual pollution $(P)$ or through the stock of available public abatement knowledge $(H)$. Thus, the same output can be achieved with less actual pollution if the firm has access to more abatement knowledge. The exponent $\varepsilon$ denotes a pollution-conversion parameter: a higher $\varepsilon$ makes pollution more effective, or equivalently, makes abatement relatively less effective. ${ }^{9}$

\footnotetext{
${ }^{7}$ Basically, endogenous growth requires non-diminishing returns to the economy's overall reproducible resources as measured at the aggregate level.

${ }^{8}$ Without loss of generality, the model ignores population growth. All variables can be interpreted as expressed per 'raw' labor unit. Also, since we normalize the size of population to unity, individual consumption represents aggregate consumption.

9 This pollution-conversion parameter $(\varepsilon)$ reflects mainly country-specific production structure or endowment conditions, and so we do not impose any prior restrictions on it. Indeed, we show how the difference between the productivities of man-made input $H$ and natural input $P$ plays a crucial role in determining optimal environmental and fiscal policy. The studies by Bovenberg and Smulders (1995, 1996) do not consider this possibility but just assume $Z=H P$ and $\varepsilon=1$.
} 


\subsection{The Decentralized Economy}

In a decentralized economy with perfect competition, each identical and spatially-homogeneous firm maximizes the firm's value by its choices of investment in private capital $K$ and pollution $P$ (ignoring the production externality from the way $P$ affects $N$ ). In equilibrium, all identical firms have the same pollution emissions, which yields the economy-wide $N$ (which could be measured as a concentration level such as micrograms per cubic foot, $\left.\mu \mathrm{g} / \mathrm{ft}^{3}\right)$.

We define $r$ as the normal required return to capital, gross of tax and gross of depreciation. This capital includes both physical and human capital, so $r K$ includes most income in the economy. Then pure profits can be defined as $\Pi=Y-\tau_{P} P-r K$, where $\tau_{P}$ denotes a tax on actual pollution (or price of pollution permits). This profit may be attributed to some fixed, non-reproducible factor that is left implicit in the model (such as raw labor). We ignore any tax on these pure profits, which would be nondistortionary, and instead model a distortionary "income tax" $\tau_{K}$ on the normal return to physical and human capital.

The value of a representative firm is the present value $V$ of all future 'dividends' $D$, where $V=\int_{0}^{\infty} e^{-r t} D(Y, \dot{K}, P) d t$, and $D(Y, \dot{K}, P)=Y-\dot{K}-\tau_{P} P$ is a stream of instantaneous dividends at each time $t$ (consistent with Bovenberg and de Mooij, 1997). These definitions imply $D=\Pi+r K-\dot{K}$, so these 'dividends' are not just part of profits, like corporate dividends. The owners of the firm receive both pure profits and normal income $r K$. Net of new investment, this flow is available for consumption, and so the present value of this flow is what owners would maximize.

Firms set the marginal product of each private input equal to its price. ${ }^{10}$ Given the total amount of natural capital, $N$, and public abatement knowledge, $H$, the firm's optimal allocation of inputs at any moment in time is governed by:

$$
\begin{aligned}
& \frac{\partial Y}{\partial K}=A(N) \frac{\partial F}{\partial K}=r \\
& \frac{\partial Y}{\partial P}=A(N) \frac{\partial F}{\partial Z} H \varepsilon P^{\varepsilon-1}=\tau_{P}
\end{aligned}
$$

\footnotetext{
${ }^{10}$ In the absence of adjustment costs, the maximization of the present value $(V)$ of future returns is equivalent to the maximization of income in each period.
} 
Thus, given available abatement techniques $H$, firms equate the marginal product of pollution to the marginal cost of pollution.

The representative household utility or social welfare $W$ is:

$$
W=\int_{0}^{\infty} e^{-\theta t} U(C, N) d t, \quad \partial U / \partial C>0, \quad \partial^{2} U / \partial C^{2}<0, \quad \partial U / \partial N \geq 0,
$$

where $U(C, N)=\frac{\left(C N^{\phi}\right)^{1-1 / \sigma}}{1-1 / \sigma}$ when $\sigma \neq 1$; and $=\ln C+\phi \ln N$ when $\sigma=1$.

In eq. (4a), consumption and environmental amenities contribute to utility, where $\theta$ is the pure rate of time preference. Eq. (4b) is a specific instantaneous utility function, where $\sigma$ is the intertemporal substitution elasticity, and $\phi$ reflects environmental preferences (or 'consumption externality' associated with the environment). ${ }^{11}$

Households own private capital, receive income from factor rentals $(r K)$, and pay tax at rate $\tau_{K}$ on it. Also, they earn profits and obtain lump-sum transfers $(G)$ from government. These income sources are used for consumption or for gross investment in private capital. Hence, the household's flow budget constraint is given by:

$$
C+\dot{K}+\delta_{K} K=\left(1-\tau_{K}\right) r K+\Pi+G
$$

The representative household chooses its consumption path and the allocation of its private capital in order to maximize lifetime utility (4a) subject to its budget (4c), taking tax rates as given. Ignoring environmental quality in the individual's maximization problem, as it is a nonrival public good, this optimization yields the modified Keynes-Ramsey rule (optimal savings rule) with the growth rate $g$ :

$$
\theta-\left(\frac{\partial \dot{U}}{\partial C}\right) / \frac{\partial U}{\partial C}=\left(1-\tau_{K}\right) r-\delta_{K} \quad \text { or } \quad g \equiv \frac{\dot{C}}{C}=\sigma\left[\left(1-\tau_{K}\right) r-\theta-\delta_{K}+\phi\left(1-\frac{1}{\sigma}\right) \frac{\dot{N}}{N}\right]
$$

\footnotetext{
${ }^{11}$ Preferences must be restricted to ensure the optimum is a balanced-growth path. Growth is balanced in the optimum only if the utility function has a special form like eq. (4b), as discussed in King et al. (1988). This specification implies that the elasticity of marginal utility is constant $\left[\left(\partial^{2} U / \partial C^{2}\right) C /(\partial U / \partial C)\right.$ $=-1 / \sigma]$, and that the share of amenities in utility is constant $[(\partial U / \partial N) N /(\partial U / \partial C) C)=\phi]$.
} 
This equation represents the trade-off between consumption and investment, and it reveals that postponement of consumption must be rewarded by a net return that compensates for the pure rate of time preference and the change over time in the marginal value of consumption (including the change in amenities). ${ }^{12}$

The government in our economy is assumed to raise revenues by adopting a positive income tax rate, $\tau_{K}$, and a positive pollution tax, $\tau_{P}{ }^{13}$ Tax revenues are used to finance government expenditures on public investment $\left(q_{H} \dot{H}+q_{H} \delta_{H} H\right)$ and lumpsum transfers to households $(G)$. Further, we suppose that government fixes the ratio of the lump-sum transfer payments relative to factor income, $\varphi \equiv G / r K$. This parameter is used below as a measure of the extent to which distorting taxes are necessary. Assuming a balanced budget at any moment, the budget constraint of government can be written as:

$$
\begin{aligned}
& \left.\tau_{K} r K+\tau_{P} P=q_{H} \dot{H}+q_{H} \delta_{H} H+G, \text { or (dividing by } r K\right), \\
& \tau_{K}+\tau_{P} P / r K=\zeta+\varphi,
\end{aligned}
$$

where $\zeta \equiv\left(q_{H} \dot{H}+q_{H} \delta_{H} H\right) / r K$ is the ratio of gross public investment in abatement knowledge to private capital income, and $\tau_{P} P / r K$ represents the ratio of pollution tax revenue to private factor income. ${ }^{14}$

In our model, the sustainable balanced-growth equilibrium path is characterized as a path where environmental quality and pollution remain constant and all other economic variables grow at a common endogenous growth rate $g$ :

$$
\begin{aligned}
& \dot{N}=\dot{P}=\dot{q}_{H}=0, \\
& \frac{\dot{Y}}{Y}=\frac{\dot{K}}{K}=\frac{\dot{H}}{H}=\frac{\dot{C}}{C}=\frac{\dot{G}}{G}=\frac{\dot{\tau}_{P}}{\tau_{P}}=g,
\end{aligned}
$$

\footnotetext{
${ }^{12}$ With sustainable balanced growth $(\dot{N}=0)$, this equation simplifies to $\dot{C} / C=\sigma\left[\left(1-\tau_{K}\right) r-\theta-\delta_{K}\right]$. As is typical of endogenous growth models, we require some inequality constraints for the growth rate to be positive $\left[\left(1-\tau_{K}\right) r-\delta_{K}>\theta\right]$ and for utility to be bounded, which corresponds to the transversality condition $\left[\theta-g(1-1 / \sigma)=\left(1-\tau_{K}\right) r-\delta_{K}-g>0\right]$.

${ }^{13}$ In the long-run equilibrium, $N$ and $P$ are constant while $K$ is growing. Therefore, on a balancedgrowth path, the marginal value of pollution, $\tau_{P}$, must increase at the growth rate $g$. See below.

${ }^{14}$ Below we define $\alpha \equiv(\partial Y / \partial Z)(Z / Y)$, the output elasticity with respect to Z. From the firm's firstorder conditions, eqs. (3a) and (3b), the ratio of pollution tax revenue to private capital income is $\tau_{P} P / r K=\alpha \varepsilon /(1-\alpha)$, which is a constant in our economy.
} 
where $g$ depends on preferences, technology, ecology, and policy. Due to condition (7b), the ratio between every pair of growing variables is also a constant. If $\varphi$ is a positive constant, then transfer payments $G$ also grow at the common growth rate.

For balanced growth to be feasible and sustainable, the production function must meet the following necessary conditions: (i) allocative variables such as $C / Y$ or $G / Y$ are constant, (ii) the production function features constant returns with respect to the growing man-made inputs $K$ and $H$, and (iii) the output elasticities of inputs in the production function remain constant over time, and their substitution elasticities are smaller than or equal to unity. ${ }^{15}$

However, the nonrival nature of both abatement knowledge capital $(H)$ and the environmental quality $(N)$ gives rise to externalities, so the decentralized solution in this economy is not optimal. The next section explores policy rules that make the decentralized economy move along the socially optimal path.

\section{Policies for Sustainable Development}

\subsection{The Optimal Corrective Government Policies}

For the market economy described above, a benevolent government can intervene to ensure the optimal provision of the two public goods $N$ and $H$. In this case, where lump-sum taxation is not available, it is important to know how the public investment in abatement knowledge is financed and what becomes of the taxes collected. Government must take as given the decentralized optimizing behavior of firms and households, eqs. (3) - (5), the ecological constraint, eq. (1), and government budget constraint, eq. (6), while affecting the allocation of resources among the three types of capital $(K, H$, and $N)$ through its policy variables $\left(\tau_{K}, \tau_{P}\right.$, and $\left.H\right)$. Then, in this second-best world, it must act to satisfy the following arbitrage condition:

$$
\left(1-\tau_{K}\right) r-\delta_{K}=\frac{1}{q_{H}} A \frac{\partial F}{\partial Z} P^{\varepsilon}+\frac{\dot{q}_{H}}{q_{H}}-\delta_{H}=\frac{1}{\tau_{P}}\left[\frac{\partial U}{\partial N} / \frac{\partial U}{\partial C}+F \frac{\partial A}{\partial N}\right]+\frac{\partial E}{\partial N}+\frac{\dot{\tau}_{P}}{\tau_{P}},
$$

\footnotetext{
15 For details on the necessary conditions for balanced endogenous growth, see Rebelo (1991), Bovenberg and Smulders (1995), Smulders and Gradus (1996), Mino (1996), and Greiner and Hanusch (1998) among others.
} 
which says that investments in the three types of capital are traded off against each other and also against household savings in eq. (5). ${ }^{16}$ The first equality in eq. (8) says that the net return on private investments $\left[\left(1-\tau_{K}\right) r-\delta_{K}\right]$ should match the return on investment in abatement knowledge (consisting of the current return in production and a capital gain). ${ }^{17}$ The second equality says that environmental quality $N$ should also earn the same rate of return. The return on environmental quality in eq. (8) consists of (i) its contribution to utility (the consumption externality), (ii) its contribution to total factor productivity (the production externality), (iii) its contribution to ecological processes (marginal absorption capacity), and (iv) a scarcity rent (capital gain).

The Hotelling rule states that if the natural resource is exhaustible, the rate of its price increase $\left(\dot{\tau}_{P} / \tau_{P}\right)$ should equal the rate of return on private capital. Hence, eq. (8) can be interpreted as a generalized Hotelling rule for a renewable natural resource with those nonrival benefits, in the presence of distortionary taxation.

Now, as is usual in this literature, assume Cobb-Douglas production technology $F(K, Z)=K^{1-\alpha} Z^{\alpha}$, where $\alpha \equiv(\partial Y / \partial Z) \cdot Z / Y$ is the aggregate output elasticity with respect to effective pollution $Z$ (and hence also to abatement knowledge stock $H$ ). ${ }^{18}$ Also, posit a simple relationship $A(N)=N^{\gamma}$, where $\gamma$ is a parameter that reflects the extent of the production externality from the stock of natural capital.

\footnotetext{
${ }^{16}$ The benevolent government can control accumulation of the three assets optimally. As in Bovenberg and Smulders $(1995,1996)$, we denote by $\lambda_{K}, \lambda_{H}$, and $\lambda_{N}$ the (current value) co-state variables associated with private capital $(K)$, abatement knowledge $(H)$, and natural capital $(N)$. Then, letting $\lambda_{K}(=\partial U / \partial C)$ be the numeraire, $q_{H}$ is the shadow price of abatement knowledge relative to private capital $\left(\lambda_{H} / \lambda_{K}\right)$, and $\tau_{P}$ is the shadow price of environmental quality relative to private capital $\left(\lambda_{N} / \lambda_{K}\right)$. From the first-order dynamic conditions for the optimal path, we then derive the canonical forms for $H$ and $N: \lambda_{K} A[\partial F / \partial Z] P^{\varepsilon}-\lambda_{H} \delta_{H}=\theta \lambda_{H}-\dot{\lambda}_{H}$ and $\partial U / \partial N+\lambda_{K} F \partial A / \partial N+\lambda_{N} \partial E / \partial N=\theta \lambda_{N}-\dot{\lambda}_{N}$, respectively. Using the above associated definitions and comparing these canonical conditions with the decentralized path in Section 1, we arrive at eq. (8): $H$ and $N$ should earn the same net rate of return as $K$, which commonly corresponds to $\theta-\dot{\lambda}_{K} / \lambda_{K}$ in eq. (5). That is, they must satisfy the intertemporal arbitrage conditions governing the law of motion of the co-state variables.

${ }^{17}$ The wedge between social and private returns on $K$ (due to $\tau_{K}$ ) leads to a shortfall of the balanced growth rate compared to a first-best world. For similar optimality conditions with distortionary taxes and public spending, see Barro and Sala-i-Martin (1995, pp.152-7) or Glomm and Ravikumar (1999).

${ }^{18}$ As usual, the Cobb-Douglas form is adopted here for balanced growth to be feasible, since $K$ and $H$ grow at the same rate and, therefore, the output elasticities with respect to these inputs are "constant" (see Bovenberg and Smulders, 1995, p.377; Rebelo, 1991, p.508). Due to the constant returns to scale assumption for $F()$, the aggregate output elasticity for private capital is $1-\alpha$. We also assume $\varepsilon \leq 1$ so that profits are not negative (a condition analogous to one in Bovenberg and de Mooij, 1997, p.214). This condition guarantees that the production function does not exhibit increasing returns with respect to private inputs $P$ and $K$. In this case, pollution $P$ also decreases in $\tau_{P}$ ceteris paribus.
} 
To investigate the optimal structure for fiscal policy, it's interesting to explore whether pollution tax revenues are enough to finance public R\&D spending on new abatement knowledge. Bovenberg and Smulders (1995, p.380) find that the ratio $q_{H} \dot{H} / \tau_{P} P$ is equal to $g / r$, which must be less than one. Thus, pollution tax revenue is always more than enough to pay for this R\&D. In our model, on the equilibrium balanced-growth path, we use eq. (3b) and the first equality of eq. (8) to show: ${ }^{19}$

$$
\frac{q_{H} \dot{H}}{\tau_{P} P}=\left(\frac{1}{\varepsilon}\right)\left(\frac{g}{\left(1-\tau_{K}\right) r-\delta_{K}+\delta_{H}}\right)
$$

(which reduces to $g / r$ in their case with no depreciation, no income tax, and $\varepsilon=1$ ). We add a distorting income tax, $\tau_{K}$, which reduces the denominator and thus raises the ratio of optimal public R\&D spending to pollution tax revenues. If $\tau_{K}$ is large enough, it could reverse the conclusion of Bovenberg and Smulders. Furthermore, we consider the possibility that $\varepsilon<1$, which means that abatement is relatively more effective, equilibrium pollution is less, and thus again pollution tax revenue could fall short of environmental $\mathrm{R} \& \mathrm{D}$ spending. The transversality condition implies $g<\left(1-\tau_{K}\right) r-\delta_{K}$, or, utility is bounded. Thus the relative size of pollution tax revenue and R\&D expenditure is ambiguous in our model with the possibility that $\varepsilon<1$. If $\varepsilon$ is low enough, in (9a), then it also could reverse Bovenberg and Smulders.

Thus, pollution tax revenue may not be enough to pay for public abatement $\mathrm{R} \& \mathrm{D}$, either because $\tau_{K}>0$ or $\varepsilon<1$ (or both). In this case, the additional needed revenue must come from raising $\tau_{K}$ above $\varphi \equiv G / r K$. Since $\tau_{K}=\varphi$ is just enough for government to pay mandatory transfers $G$, the additional tax needed can be measured by $\tau_{K}-\varphi$, the extent to which $\tau_{K}$ exceeds the level necessary to pay for $G:{ }^{20}$

$$
\tau_{K}-\varphi=\left(\frac{\alpha}{1-\alpha}\right)\left(\frac{g+\delta_{H}}{\left(1-\tau_{K}\right) r-\delta_{K}+\delta_{H}}-\varepsilon\right) \lessgtr 0
$$

All parameters on the right hand side of ( $9 \mathrm{~b}$ ) help determine whether pollution tax revenue falls short of abatement spending in a way that requires more income tax.

19 On the equilibrium balanced-growth path, from eq. (7) we know $\dot{q}_{H}=0$ and $\dot{H}=g H$. Then, plugging this into the first equality of eq. (8) and using $A[\partial F / \partial Z] H \varepsilon P^{i}=\tau_{P} P$ from eq. (3b) yields $\left(1-\tau_{K}\right) r-\delta_{K}=\left(\tau_{P} P / q_{H} \dot{H}\right)(g / \varepsilon)-\delta_{H}$.

${ }^{20}$ Substituting eq. (9a) into eq. (6b) and using $\tau_{P} P / r K=\alpha \varepsilon /(1-\alpha)$ and $\dot{H}=g H$ yields eq. (9b). 
Next, the long-run growth rate of all variables can be determined using eqs. (1) (8) above. To reformulate the whole dynamic system of the economy into a more simplified framework, define three new "fundamental" variables that are constant on the balanced-growth path: $h \equiv H / K, c \equiv C / K$, and $\tau \equiv \tau_{P} / K$. Appendix A derives conditions for the optimal balanced-growth equilibrium values $\left(h^{*}, c^{*}, N^{*}, \tau^{*}, \mathrm{~g}^{*}, r^{*}\right.$, and $\tau_{K}{ }^{*}$ ), governed by the government budget constraint in eq. (6), the dynamic equilibrium conditions in eq. (7), and the inter-asset arbitrage conditions in eq. (8): ${ }^{21}$

$$
\begin{aligned}
& h^{*}=E\left(N^{*}\right)^{\frac{1-\alpha \varepsilon}{\alpha}} N^{*} \frac{-\gamma}{\alpha}\left(\frac{\tau^{*}}{\alpha \varepsilon}\right)^{\frac{1}{\alpha}} \\
& c^{*}=\left[\frac{1}{1-\alpha}-\left(\frac{\alpha \varepsilon}{1-\alpha}+\tau_{K}^{*}-\varphi\right) / h^{*}\right] r^{*}+\delta_{H}-\delta_{K} \\
& {\left[\sigma\left(1-\tau_{K}{ }^{*}\right)-\left(\frac{\alpha \varepsilon}{1-\alpha}+\tau_{K}^{*}-\varphi\right) / h^{*}\right] r^{*}-\sigma\left(\theta+\delta_{K}\right)+\delta_{H}=0} \\
& \left.\left(-\frac{1}{\tau^{*} N^{*}} \frac{\gamma}{1-\alpha}-\frac{\alpha(1-\varepsilon)}{1-\alpha}-\varphi\right)\right) r^{*}+\left(1-\frac{\phi}{\tau^{*} N^{*}}\right) c^{*}-E^{\prime}\left(N^{*}\right)=0 \\
& g^{*}=\sigma\left[\left(1-\tau_{K}^{*}\right) r^{*}-\theta-\delta_{K}\right] \\
& r^{*}=\frac{1-\alpha}{\alpha \varepsilon} \tau^{*} E\left(N^{*}\right) \\
& \tau_{K}^{*}=1-\left(\frac{\alpha}{1-\alpha}\right) / h^{*}+\frac{\delta_{H}-\delta_{K}}{r^{*}} .
\end{aligned}
$$
$(\operatorname{tax}$ efficiency) $(10 \mathrm{~g})$

Note that eqs. (10) represent seven equations in seven unknowns $\left(h^{*}, c^{*}, N^{*}, \tau^{*}\right.$, $\mathrm{g}^{*}, r^{*}$, and $\left.\tau_{K}{ }^{*}\right)$. They are not linear in those unknowns, however, and so closed-form solutions are not available. Instead, we first offer interpretations and discussion of how these equations can be used to characterize optimal policy instruments, and second, we later provide numerical solutions.

Eqs. (10a) and (10b) determine the optimal equilibrium abatement knowledge ( $h$ $\equiv H / K)$ and consumption $(c \equiv C / K)$ relative to private capital. With a wedge between the private and social returns to private capital, eq. (10c) uses the modified KeynesRamsey rule describing the optimal savings-investment path for private capital. Then eq. (10d) shows the socially-optimal choice for natural capital $(N)$, where the marginal

\footnotetext{
${ }^{21}$ Without loss of generality, we now assume that $q_{H}$ is normalized to unity in the steady-state.
} 
benefit equals its marginal cost. From eq. (5) and eq. (7), note that eq. (10e) allows us to solve for the equilibrium growth rate $g$ as one of the endogenous variables of the system. Then eq. (10f) shows the equilibrium gross-of-tax return to private capital, determined by the product of the pollution tax relative to private capital $\left(\tau \equiv \tau_{P} / K\right)$ times the absorption capacity of the environment $(P=E(N))$ along the balanced-growth path. Finally, eq. $(10 \mathrm{~g})$ determines $\tau_{K}$ using the arbitrage condition between private capital and abatement knowledge capital. Social optimality requires that government set the levels of corrective policy instruments, $\tau$ and $\tau_{K}$, according to eqs. (10).

The growth rate $g^{*}$ is not just from eq. (10e), because the other endogenous variables in that equation depend on all parameters in the entire system. Thus, the optimal long-run equilibrium growth path of the economy depends critically not just on the intertemporal substitution elasticity $(\sigma)$ and the pure rate of time preference $(\theta)$, but also on the necessary income tax distortion $(\varphi \equiv G / r K)$, the environmental preference parameter $(\phi)$, the environmental production externality parameter $(\gamma)$, the production elasticity of abatement knowledge $(\alpha)$, the pollution-conversion parameter $(\varepsilon)$, the depreciation rates for man-made capitals $\left(\delta_{K}\right.$ and $\left.\delta_{H}\right)$, and the ecological components behind the absorption capacity function $E(N)$.

In particular, eqs. (10b-d) reveal that the extent to which government spending requires distortionary taxation, $\varphi$, has critical effects on the optimal configurations of the corrective policy instruments $\left(\tau_{K}^{*}, h^{*}\right.$, and $\left.\tau^{*}\right)$. That is, the levels of the optimal corrective government polices must be quite different from those in the Bovenberg and Smulders $(1995,1996)$ first-best world where $\varphi=0$.

How exactly does the need for more distortionary revenue $(\varphi)$ affect the optimal use of pollution tax $\left(\tau_{P}\right)$ relative to income tax $\left(\tau_{K}\right)$ ? To see directly how the key parameters affect the second-best optimal government policy rules, we would need closed-form solutions for the system of seven equations with seven unknowns. With no explicit analytical solutions, however, we next proceed numerically. We select initial parameter values that roughly reflect the case of global warming, and then we alter each key parameter to conduct a numerical sensitivity analysis. ${ }^{22}$

\footnotetext{
${ }^{22}$ These simulations were performed using the GAMS/MINOS5 algorithm (Brooke et al., 1992).
} 


\subsection{A Numerical Simulation for the Case of Global Warming}

In choosing "central" parameter values, we rely primarily on values that are frequently used in the relevant literature. The parameters chosen from Barro and Salai-Martin (1995) and Bovenverg and Smulders $(1995,1996)$ are: $\alpha=0.24, \sigma=0.67$, $\delta_{K}=0.08, \delta_{H}=0.05$, and $\theta=0.03$. The absorption capacity function $E(N)$ is specified by the form $\beta N(1-N)$, where $N \in(0.5,1)$, and the embedded ecological parameter $\beta$ is chosen as 0.04 from Nordhaus (1994, Chapter 3) to ensure a steady state with positive ratios (e.g., $C / Y$ ). ${ }^{23}$ The parameter $\varphi$ is set to 0.25 , to account for the revenue required for non-productive government spending (transfer payments). Remaining parameters are chosen so that the model can reproduce plausible growth rates for the U.S. economy. The central values for those variables are chosen as $\gamma=$ $0.77, \phi=0.70$, and $\varepsilon=0.75$, but each is also varied to test the sensitivity of results.

In Table 1, Row A uses those "central" parameter values and shows the outcome for optimal policy rates in the normalized U.S. economy. On the balanced-growth equilibrium path, the value of $\tau \equiv \tau_{P} / K$ is the ratio of two growing variables and is 14.50 for this normalized economy (calibrated to the US). The optimal environmental investment ratio $H / K$ is 0.619 in this table. From a similar model in Barro (1990), we might infer that this ratio should be $\alpha /(1-\alpha)$, based on the 'pure' output elasticity, a ratio that is only 0.315 using our parameters. ${ }^{24}$ Note, however, that Barro's conjecture ignores distortionary taxation and environmental externalities. As shown below, our model with no tax distortions yields $H / K=0.401$, much closer to Barro's 0.315 . The remaining difference reflects a "premium for environmental sustainability" (the social value of environmental quality attributable to $\phi$ and $\gamma$ ). This premium disappears as both of these externality parameters approach zero. ${ }^{25}$

\footnotetext{
${ }^{23}$ For the case of global warming, we define environmental quality $N$ as the difference between the catastrophic stock level of GHG concentration $(\bar{S})$ and its current accumulation level $\left(S=\int_{-\infty}^{t} P_{t} d t\right)$. The carrying capacity is normalized to unity. The economy here is also assumed to be above the point of maximum sustainable yield (which occurs at $N=0.5$ ).

${ }^{24}$ In his simple model with public investment and endogenous growth, Barro does not consider the environment or abatement R\&D exactly. But our $H$ corresponds to his production function input of government-provided nonrival public services, such as from infrastructure.

${ }^{25}$ Start with our central case, but where $\varphi=0.00$ and $\varepsilon=1.00$. Then, as the externalities $\phi$ and $\gamma$ approach zero, we find that $H / K$ approaches 0.315 , and the sustainability premium disappears.
} 
Table 1. Sensitivity of Optimal Steady-State Values to Key Parameters

\begin{tabular}{|c|c|c|c|c|c|c|}
\hline & $\tau$ & $\tau_{K}$ & $N$ & $H / K$ & $C / K$ & $g$ \\
\hline A. Central case & 14.50 & 0.358 & 0.898 & 0.619 & 0.064 & 0.0238 \\
\hline \multicolumn{7}{|l|}{$\begin{array}{l}\text { B. General parameters } \\
\text { 1. Intertemporal substitution }(\sigma)\end{array}$} \\
\hline a. Low $(0.33)$ & 6.79 & 0.235 & 0.751 & 0.505 & 0.110 & 0.0178 \\
\hline b. Central case (0.67) & 14.50 & 0.358 & 0.898 & 0.619 & 0.064 & 0.0238 \\
\hline c. High $(0.90)$ & 17.70 & 0.377 & 0.917 & 0.645 & 0.057 & 0.0212 \\
\hline \multicolumn{7}{|l|}{ 2. Time preference rate $(\theta)$} \\
\hline a. Lowered 20 percent $(0.024)$ & 16.97 & 0.372 & 0.913 & 0.638 & 0.059 & 0.0242 \\
\hline b. Central case $(0.03)$ & 14.50 & 0.358 & 0.898 & 0.619 & 0.064 & 0.0238 \\
\hline c. Raised 20 percent $(0.036)$ & 13.17 & 0.345 & 0.884 & 0.604 & 0.069 & 0.0225 \\
\hline \multicolumn{7}{|c|}{ 3. Other Government Spending $(\varphi)$} \\
\hline a. No transfers $(0.0)$ & 8.63 & 0.068 & 0.827 & 0.401 & 0.022 & 0.0554 \\
\hline b. Central case $(0.25)$ & 14.50 & 0.358 & 0.898 & 0.619 & 0.064 & 0.0238 \\
\hline c. High transfers $(0.35)$ & 22.64 & 0.502 & 0.934 & 0.854 & 0.086 & 0.0047 \\
\hline \multicolumn{7}{|l|}{ C. Environment-related parameters } \\
\hline $\begin{array}{l}\text { 1. Environmental preference }(\phi) \\
\text { a. Low concern }(0.3)\end{array}$ & 12.90 & 0355 & 0880 & 0615 & 0066 & 00248 \\
\hline b. Central case $(0.7)$ & 14.50 & 0.358 & $\begin{array}{l}0.000 \\
0.898\end{array}$ & 0.619 & $\begin{array}{l}0.066 \\
0.064\end{array}$ & $\begin{array}{l}0.0248 \\
0.0238\end{array}$ \\
\hline c. High concern (1.5) & 16.38 & 0.360 & 0.911 & 0.623 & 0.062 & 0.0225 \\
\hline \multicolumn{7}{|l|}{ 2. Environmental productivity $(\gamma)$} \\
\hline a. Low externality $(0.3)$ & 11.08 & 0.340 & 0.843 & 0.586 & 0.077 & 0.0351 \\
\hline b. Central case $(0.77)$ & 14.50 & 0.358 & 0.898 & 0.619 & 0.064 & 0.0238 \\
\hline c. High externality (1.2) & 20.12 & 0.373 & 0.932 & 0.647 & 0.056 & 0.0162 \\
\hline \multicolumn{7}{|l|}{ 3. Ecological capacity factor $(\beta)$} \\
\hline a. Lowered 20 percent $(0.032)$ & 21.84 & 0.371 & 0.921 & 0.644 & 0.057 & 0.0169 \\
\hline b. Central case $(0.04)$ & 14.50 & 0.358 & 0.898 & 0.619 & 0.064 & 0.0238 \\
\hline c. Raised 20 percent $(0.048)$ & 11.32 & 0.349 & 0.883 & 0.604 & 0.069 & 0.0284 \\
\hline \multicolumn{7}{|l|}{ 4. Pollution-conversion factor $(\varepsilon)$} \\
\hline a. Lowered 20 percent $(0.6)$ & 14.07 & 0.364 & 0.893 & 0.615 & 0.076 & 0.0295 \\
\hline b. Central case $(0.75)$ & 14.50 & 0.358 & 0.898 & 0.619 & 0.064 & 0.0238 \\
\hline c. Raised 20 percent $(0.9)$ & 15.04 & 0.352 & 0.901 & 0.624 & 0.053 & 0.0181 \\
\hline
\end{tabular}

We now turn to sensitivity analysis. In panel B of Table 1 we consider the usual non-environmental parameters, just to confirm that results from our model are consistent with those of previous models. As seen in rows Bla to B1c, a society with a higher intertemporal substitution elasticity $(\sigma)$ optimally invests more in productive assets, since it is flexible enough to put off consumption to a later date. Thus $K$ rises, and $C / K$ falls. To invest more in other assets like abatement knowledge $(H)$ and improved environmental quality $(N)$, the government raises its R\&D and its pollution levy $(\tau)$. In the case of extremely low $\sigma$, the income tax could fall below the rate needed to pay for lump-sum transfers $\left(\tau_{K}<\varphi=0.25\right)$. Then the pollution tax can pay for all abatement $R \& D$ and still help finance transfers. 
Next, rows B2a to $\mathrm{B} 2 \mathrm{c}$ show that an increase in the pure rate of time preference $(\theta)$ reduces optimum steady-state investment in knowledge $(H)$, environmental quality $(N)$, and private capital. The lower $K$ raises $C / K$. An impatient society invests less in productive assets, thereby leading to a lower long-run growth rate.

Required other government spending, $\varphi$, is a non-environmental parameter with important implications for environmental policy. Using static second-best models with labor taxes, Metcalf (2003) and Gaube (2005) ask if increases in other public goods crowd out provision of the environmental public good. Because more public spending leads to higher labor taxes and pollution taxes, they find that it can improve the environment. ${ }^{26}$ Our results are consistent with these studies of environmental taxation in second-best, but we extend the model to a dynamic setting. Rows B3a to B3c indicate that an increase in $\varphi$ (from 0.0 to 0.35 ) raises optimal values of both the tax on capital income and the tax on pollution. It lowers the optimal long-run growth rate $g$ (from .0554 to .0047), but it improves the environment $N$ (from .827 to .934). ${ }^{27}$

In our dynamic model, higher public spending raises both tax rates and thus has two effects that both increase environmental quality. First, the higher $\tau_{P}$ reduces pollution directly. Second, the higher $\tau_{K}$ makes the accumulation of private capital more costly relative to other types of capital such as abatement knowledge or natural capital. The government increases abatement knowledge by its R\&D spending, which also improves the environment. These increases in taxes on pollution and income lead to better environmental quality but a lower stock of private capital, and to a higher ratio of consumption to private capital (due to both increased transfer payments and decreased private capital). Which tax rate increases relatively more? Initial increases in $\varphi$ (from 0.0 to 0.25 ) raise $\tau_{K}$ proportionately more than $\tau$, while further increases (to 0.35 ) raise $\tau$ more than $\tau_{K}$.

\footnotetext{
${ }^{26}$ Metcalf (2003) looks at a marginal change in spending that requires more distortionary tax, whereas Gaube (2005) finds that environmental quality is higher in second best with distorting taxes than in first best with a lump sum tax (provided that marginal revenue from the pollution tax is positive).

${ }^{27}$ To facilitate a direct comparison to the model of Bovenberg and Smulders (1995), we also calculate results for their first-best case where lump-sum taxes are available (that is, our central case but with $\tau_{K}$ $=0, \varphi=0$, and $\varepsilon=1)$. Compared to our central case, the pollution tax is lower $(\tau=9.42)$ and environmental quality is lower $(N=0.851)$. Again, distortionary taxation is good for the environment, even if it is not necessarily good for growth or welfare.
} 
We now vary parameters that specifically relate to the environment. If consumers care more about the environment (as $\phi$ increases from 0.3 to 1.5 in rows $\mathrm{C} 1$ a to $\mathrm{C} 1 \mathrm{c})$, then the optimal abatement knowledge intensity of production $(H / K)$ and natural capital stock $(N)$ both increase at the expense of consumption. The same outcomes occur with an increase in $\gamma$, the productivity of the environment (rising from 0.3 to 1.2 in rows $\mathrm{C} 2$ a to $\mathrm{C} 2 \mathrm{c}$ ). The higher $\phi$ or $\gamma$ calls for more ambitious environmental policy and slower economic growth in the optimum steady-state.

A higher ecological parameter, $\beta$, raises marginal absorption capacity through the assumption that $E(N)=\beta N(1-N)$. It thus affects how the economy and the environment interact. The results in rows $\mathrm{C} 3 \mathrm{a}$ to $\mathrm{C} 3 \mathrm{c}$ indicate that an increased $\beta$ (from 0.032 to 0.048 ) makes it easier for the economy to pollute without depleting natural capital, and thus to achieve a higher sustainable growth rate (from 0.0169 to 0.0284 ) with less stringent environmental and tax policies ( $\tau$ decreases from 21.84 to 11.32, while $\tau_{K}$ falls from 0.371 to 0.349 ).

Finally, consider our added pollution-conversion parameter, $\varepsilon$. Higher $\varepsilon$ makes pollution more effective, so firms want to use more pollution. As shown in rows $\mathrm{C} 4 \mathrm{a}$ to $\mathrm{C} 4 \mathrm{c}$, the government responds optimally with a higher pollution tax $(\tau)$, more abatement $(H / K)$, and better environment $(N)$, all at the expense of consumption and growth. ${ }^{28}$ As implied by eq. (9b), however, an increase in $\varepsilon$ (from 0.6 to 0.9 ) leads to a decrease in $\tau_{K}$ (from 0.364 to 0.352 ). The important result here is how the welfare maximizing 'mix' of environmental and capital taxes depends on this parameter. For a given pollution tax rate, a higher $\varepsilon$ makes pollution more productive and raises the pollution tax base $(\alpha \varepsilon Y)$. Since the pollution tax becomes a more efficient instrument to raise revenue, the optimal $\tau$ is higher and $\tau_{K}$ is lower. Thus, $\varepsilon$ plays a critical role when integrating environmental taxes with distortionary income taxes.

\subsection{Growth and Welfare Implications of Tighter Environmental Policies}

How are growth and welfare affected by a tighter environmental policy in the presence of externalities and distortionary taxation? Early models with exogenous

\footnotetext{
${ }^{28}$ Conversely, relative to Bovenberg and Smulders (1995) with $\varepsilon=1$, our central case with $\varepsilon=0.75$ implies that abatement R\&D is relatively more effective, so government doesn't need to provide as much of it. The optimal $\tau$ and $N$ are lower, but consumption and growth are higher.
} 
technological progress found that pollution control raises abatement costs and thus hurts short-run growth (and long-run levels). ${ }^{29}$ Later models with endogenous growth allow environmental policy to have permanent effects on the growth rate, even in the long-run (e.g., Bovenberg and Smulders, 1996; Hettich, 1998). If pollution taxes are sub-optimally low, for example, then pollution is excessive. Natural capital is then under-accumulated, which affects production.

That recent endogenous growth literature has argued that a tighter environmental policy can have positive effects on growth in the long-run. In this section, however, we show that this view may be too optimistic. With our introduction of distortionary taxes and $\varepsilon \neq 1$, we show how a higher pollution tax may reduce growth, even if it does maximize welfare. To see this, suppose our economy is on the optimal balanced growth path, so $d W / d \tau=0$. We then derive an expression for $d g / d \tau$ and show that the sign could be positive or negative, so that a tighter pollution policy might still raise or lower growth. That is, maximizing welfare is not the same as maximizing growth.

To investigate the growth effects of tighter environmental policy, substitute eq. (10f) into (10e) and totally differentiate $g$ with respect to $\tau$. The long-run growth rate then reacts to changes in pollution taxation as:

$$
\frac{d g}{d \tau}=-\sigma\left(\frac{d \tau_{K}}{d \tau}\right) r+\sigma\left(1-\tau_{K}\right) \frac{1-\alpha}{\alpha \varepsilon} E(N)\left(1-\eta_{E N} \eta_{N \tau}\right)
$$

where $\eta_{E N}(\equiv-(d E / d N)(N / E))$ is the elasticity of the absorption capacity of the environment with respect to natural capital, and $\eta_{N \tau}(\equiv(d N / d \tau)(\tau / N))$ is the elasticity of natural capital with respect to the pollution tax. ${ }^{30}$

The first term on the right-hand side in eq. (11) represents the marginal 'taxreplacement effect'. On the normal side of the Laffer curve, raising the pollution tax rate can mean a lower capital tax $\left(d \tau_{K} / d \tau<0\right)$. Since $r$ and $\sigma$ are positive, the whole first term is positive. Thus, substitution of environmental taxes for income taxes ceteris paribus stimulates economic growth through less taxation of capital. The second term reflects the 'productivity effect' of a higher $\tau$. In this model, a tighter

\footnotetext{
${ }^{29}$ Among others, see Jorgenson and Wilcoxen (1990), Nordhaus (1994), and Goulder (1995).

${ }^{30}$ The elasticity $\eta_{E N}$ is not constant along $E(N)$, and it depends critically on the shape of that curve, but note that $\partial E / \partial N<0$ from our assumption of dynamically stable equilibrium (as in footnote 6 above).
} 
environmental policy is sure to stimulate growth as long as it has a positive productivity effect. Each component is known to be positive except for the last component: if $\eta_{E N} \cdot \eta_{N \tau}>1$, then the whole second term is negative, and it could swamp the first term such that a higher $\tau$ reduces growth.

Yet eq. (11) holds only at the optimum. Therefore, we now show more generally that environmental policy can have opposite effects on growth and welfare. Consider a balanced path that may not be optimal (ignoring transitional dynamics). ${ }^{31}$ In Appendix B, we derive the following general relationship:

$$
\frac{d W}{d \tau}=\frac{K(0)\left(C(0) N^{\phi}\right)^{-1 / \sigma}}{\theta-g(1-1 / \sigma)}\left(\frac{1-\alpha}{\alpha \varepsilon} E(N) N^{\phi}\right)\left(\frac{\alpha(1-\varepsilon)}{1-\alpha}+\varphi\right)\left[1+\left(\phi-\eta_{E N}\right) \eta_{N \tau}\right]+\frac{\partial W}{\partial g} \frac{d g}{d \tau}
$$

where $K(0)$ is the initial capital stock, and $C(0)$ is initial consumption.

The long first term of eq. (12) has several parts, but the component $[\alpha(1-\varepsilon) /(1-\alpha)+\varphi]$ is zero in the special case of the previous literature where $\varepsilon=1$ and $\varphi=0$. In this case, then, the whole long first term is zero. In the second term, Appendix B shows that $\partial W / \partial g$ is positive, which means that the effect of a tax change on welfare on the left hand side, $d W / d \tau$, always has the same sign as the effect on growth, $d g / d \tau$ (for a formal proof, see Greiner and Hanusch, 1998, p.258). In other words, while Bovenberg and Smulders (1996) do consider transitional dynamics, their model with no transitional dynamics would imply that maximizing growth always means maximizing welfare, and vice versa.

More generally, the total effect depends on the sign of the long first term in (12). With the assumption that $[\theta-g(1-1 / \sigma)]>0$, the first ratio is positive. Suppose also, for the moment, that $\left[1+\left(\phi-\eta_{E N}\right) \eta_{N \tau}\right]>0$. Then the whole long first term is positive with either of the generalizations allowed in this paper, namely $\varepsilon<1$ or $\varphi>0$.

This case is shown in Figure 2a. At the growth-maximizing tax rate where $d g / d \tau=0$, the positive first term in (12) means that $d W / d \tau$ is positive - and the curve for $W$ is still rising. In other words, if government spending requires distortionary taxation, then pollution taxes negatively affect growth, even at the welfare optimum.

\footnotetext{
${ }^{31}$ For analytical tractability, we ignore transitional dynamics off the balanced growth path. As shown by Futagami and Mino (1995), transitional dynamics also mean that a policy may have opposite effects on growth and welfare. The advantage of limiting the analysis to balanced growth paths is that we can show analytically how these two targets may have different responses to a tighter environmental policy in the long run. For a similar analysis on income taxation, see Greiner and Hanusch (1998).
} 


\section{Figure 2: Optimal Environmental Policy}

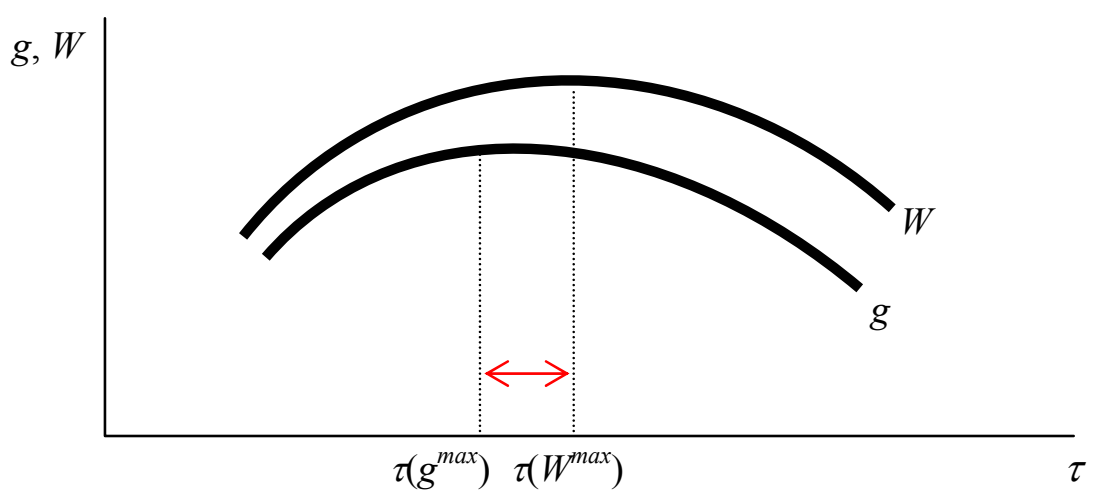

(a) $\tau\left(g^{\max }\right)$ is less than $\tau\left(W^{\max }\right)$

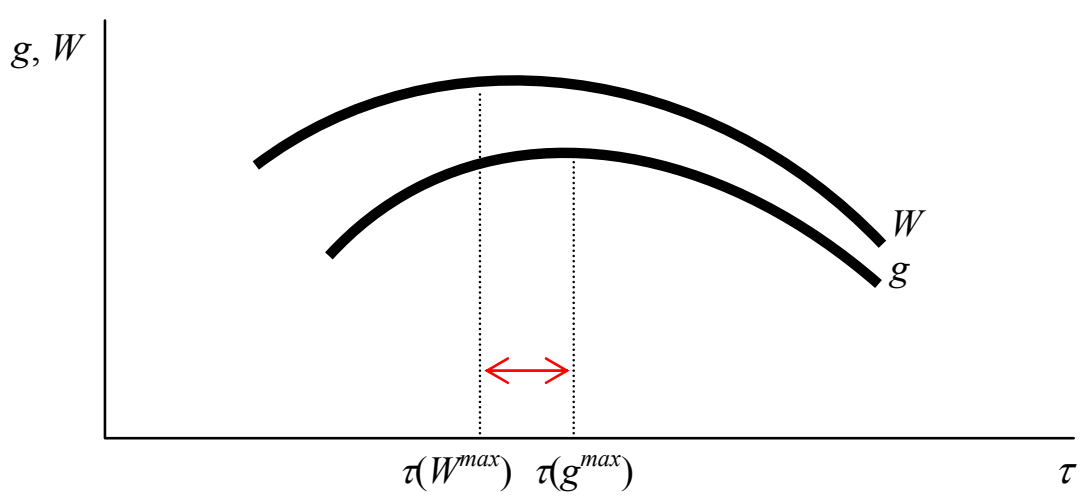

(b) $\tau\left(g^{\max }\right)$ is greater than $\tau\left(W^{\max }\right)$

Figure $2 \mathrm{~b}$ shows the opposite case where the long first term in (12) is negative. This case could arise, for example, if $\varphi=G / r K$ is negative, meaning that government collects a lump sum tax. ${ }^{32}$ It could also arise if the last component of the long first term is negative, that is, if $\left[1+\left(\phi-\eta_{E N}\right) \eta_{N \tau}\right]<0$. This possibility would require that the environmental preference $\phi$ is small relative to the absorption elasticity $\eta_{E N}$. Still, the long first term in (12) would have to be sufficiently negative to swamp the partial effect in the last term to see the case in Figure $2 \mathrm{~b}$ where an increase in $\tau$ could increase growth while reducing welfare.

In general, maximizing growth is not equivalent to maximizing welfare, and the first term in eq. (12) reveals the difference. The key parameters affecting this

\footnotetext{
${ }^{32}$ A lower bound on $\varphi$ is given by the condition that private consumption is positive.
} 
difference are the size of tax distortions $(\varphi)$, the productivity of pollution $(\varepsilon)$, the environmental externality in utility $(\phi)$, plus the elasticities $\eta_{E N}$ and $\eta_{N \tau}$. At the growth-maximizing policy where $d g / d \tau=0$, welfare still increases with $\tau$ if the first term is positive (due to $\varepsilon<1, \varphi>0$, or both). Using our central case parameters where $\varepsilon=0.75$ and $\varphi=0.25$, we find that the growth maximizing pollution tax is 10.20, much less than the welfare maximizing rate of 14.50 .

\section{Conclusions}

This paper develops a model of endogenous growth, distortionary taxation, and environmental quality. We incorporate private capital accumulation, abatement knowledge as a productive asset, and the natural environment as a renewable resource. These three assets evolve by the endogenous flows of private savings or human capital formation, public R\&D investment, pollution, and ecological regeneration. Each of these features has appeared before, but we describe how results from our combined model differ from results of each prior model. In particular, we focus on parameters representing public spending that requires distorting taxes $(\varphi)$ and the productivity of abatement knowledge relative to pollution $(\varepsilon)$.

Our model does not include all possible features, however, and so future research could consider other extensions as well. First, we look only at long run balanced growth paths, whereas results might differ during transitions from one path to another (Bovenberg and Smulders, 1996). Second, we add a distorting income tax, but results might differ for other distorting taxes on consumption or wages (Hettich, 1998). Third, we consider public abatement spending, but the government could also or instead provide incentives for private abatement R\&D (Smulders and Gradus, 1996).

Still, using our model, we provide new answers to five primary questions. First, while prior research finds that pollution tax revenues are always enough to pay for optimal public spending on abatement, our extensions can reverse that conclusion. Second, while prior research finds that the optimal public capital relative to private capital depends on output elasticities, we show how the addition of tax distortions and externalities substantially change that answer. Third, while prior static models ask whether other public goods "crowd out" provision of the environmental public good, we address this question in a dynamic model. Fourth, we ask whether greater need for 
public revenue means larger increases in the distorting income tax or in the pollution tax. Initial increases in the income tax are larger, but we find that further public spending implies larger relative increases in the pollution tax. Fifth, while others find that a higher pollution tax can raise economic growth, we look near the welfare maximum and find that a higher pollution tax might raise or lower growth.

\section{Appendix A: The Equilibrium Dynamics of the Economy}

From eqs. (3), (4), and (6), the growth rates of the two man-made capital stocks are then: $\dot{H} / H=\left[\alpha \varepsilon /(1-\alpha)+\tau_{K}-\varphi\right] r K / H-\delta_{H}$ and $\dot{K} / K=\left[1 /(1-\alpha)-\left(\alpha \varepsilon /(1-\alpha)+\tau_{K}\right.\right.$ $-\varphi)] r-C / K-\delta_{K}$. Using eq. (8), the growth rate of $\tau_{P}$ is: $\dot{\tau}_{P} / \tau_{P}=-\left(\tau_{P} N / K\right)^{-1}$ $[\phi C / K+\gamma /(1-\alpha) r]-\partial E(N) / \partial N+\left(1-\tau_{K}\right) r-\delta_{K}$. Then, using the definition of the three new "fundamental" variables (i.e., $h \equiv H / K, c \equiv C / K$, and $\tau \equiv \tau_{P} / K$ ) that are constant along the balanced-growth path, we can reformulate the whole (transitional) dynamic system of the economy in terms of $h, c, N, \tau$ and $q_{H}$ as:

$$
\begin{aligned}
& \frac{\dot{h}}{h}\left(\equiv \frac{\dot{H}}{H}-\frac{\dot{K}}{K}\right)=\left(\left(\frac{\alpha \varepsilon}{1-\alpha}+\tau_{K}-\varphi\right)(1+1 / h)-\frac{1}{1-\alpha}\right) r+c+\delta_{K}-\delta_{H} \\
& \frac{\dot{c}}{c}\left(\equiv \frac{\dot{C}}{C}-\frac{\dot{K}}{K}\right)=\left(\sigma\left(1-\tau_{K}\right)+\left(\frac{\alpha \varepsilon}{1-\alpha}+\tau_{K}-\varphi\right)-\frac{1}{1-\alpha}\right) r+c-\sigma\left(\theta+\delta_{K}\right)+\delta_{H} \\
& +\phi(\sigma-1) \frac{E(N)-P}{N} \\
& \dot{N}=E(N)-P \\
& \frac{\dot{\tau}}{\tau}\left(\equiv \frac{\dot{\tau}_{P}}{\dot{\tau}_{P}}-\frac{\dot{K}}{K}\right)=\left(-\frac{1}{\tau N} \frac{\gamma}{1-\alpha}+1-\frac{1}{1-\alpha}+\left(\frac{\alpha \varepsilon}{1-\alpha}-\varphi\right)\right) r+\left(1-\frac{\phi}{\tau N}\right) c-\frac{\partial E(N)}{\partial N} \\
& \frac{\dot{q}_{H}}{q_{H}}=\left(-\frac{1}{q_{H}}\left(\frac{\alpha}{1-\alpha}\right) / h+\left(1-\tau_{K}\right)\right) r+\delta_{H}-\delta_{K} \\
& \text { where } \quad r=(1-\alpha)\left(\frac{\tau}{\alpha \varepsilon}\right)^{\frac{-\alpha \varepsilon}{1-\alpha \varepsilon}} N^{\frac{\gamma}{1-\alpha \varepsilon}} h^{\frac{\alpha}{1-\alpha \varepsilon}} \text { and } P=\left(\frac{\tau}{\alpha \varepsilon}\right)^{\frac{-1}{1-\alpha \varepsilon}} N^{\frac{\gamma}{1-\alpha \varepsilon}} h^{\frac{\alpha}{1-\alpha \varepsilon}} \text {. }
\end{aligned}
$$

As implied in eq. (7), the steady-state equilibrium for the dynamic system in eqs. (A.1) - (A.5) above can readily be found by setting the five time-derivatives to zero (i.e., $\dot{h}=\dot{c}=\dot{N}=\dot{\tau}=\dot{q}_{H}=0$ ). The absence of non-convexities guarantees the existence of the equilibrium dynamic path. Letting $\left(h^{*}, c^{*}, N^{*}, \tau^{*}\right)$ be the optimal 
balanced-growth equilibrium values of $(h, c, N, \tau)$, governed by the inter-asset arbitrage conditions in eq. (8), we finally arrive at the eqs. (10a) - (10g) in the text.

\section{Appendix B: Derivation of Effects on Welfare and Growth}

To calculate the welfare effects of a tighter environmental policy starting at time $t=0$, first compute utility in eq. (4a) on the initial, sub-optimal balanced-growth path:

$$
\begin{aligned}
W(\mathrm{~g}) & =\frac{\left(C(0) N^{\phi}\right)^{1-1 / \sigma}}{1-1 / \sigma} \frac{1}{\theta-g(1-1 / \sigma)}, \text { if } \sigma \neq 1 ; \text { and } \\
= & \frac{(\ln C(0)+\phi \ln N) \theta+g}{\theta^{2}}, \text { if } \sigma=1,
\end{aligned}
$$

where $C(0)$ is the initial consumption level. With $\theta-g(1-1 / \sigma)=\left(1-\tau_{K}\right) r-\delta_{K}-g$, we assume this value is positive, so that utility in eq. (4a) remains bounded. Also, differentiating eq. (B.1) with respect to $g$, we can see that $\partial \mathrm{W} / \partial \mathrm{g}>0$.

Substituting eqs. (10f) and $(10 \mathrm{~g})$ into the growth rate for $C, H$, and $K$ on the balanced-growth path yields:

$$
C(0)=K(0)\left[\left(\frac{\alpha(1-\varepsilon)}{1-\alpha}+\varphi\right) \frac{1-\alpha}{\alpha \varepsilon} E(N) \tau+\left(\frac{1}{\sigma}-1\right) g+\theta\right]
$$

where $K(0)$ is the level of private capital stock at $t=0$. Finally, insert eq. (B.2) into eq. (B.1), and totally differentiate $W(\cdot)$ with respect to $\tau$ to obtain eq. (12) in the text.

\section{References}

Barro, R., 1990, Government Spending in a Simple Model of Endogenous Growth, Journal of Political Economy 98(5), s103-25.

Barro, R. and X. Sala-i-Martin, 1992, Public Finance in Models of Endogenous Growth, Review of Economic Studies 59(4), 645-61.

Barro, R. and X. Sala-i-Martin, 1995, Economic Growth, McGraw-Hill, New York.

Bovenberg, A. and R. de Mooij, 1997, Environmental Tax Reform and Endogenous Growth, Journal of Public Economics 63(2), 207-37. 
Bovenberg, A. and S. Smulders, 1995, Environmental Quality and Pollutionaugmenting Technical Change in a Two-sector Endogenous Growth Model, Journal of Public Economics 57(3), 369-91.

Bovenberg, A. and S. Smulders, 1996, Transitional Impacts of Environmental Policy in an Endogenous Growth Model, International Economic Review 37(4), 861-93.

Brooke, A., D. Kendrick, and A. Meeraus, 1992, GAMS: A User's Guide, The Scientific Press, South San Francisco, CA.

Elbasha, E. and T. Roe, 1996, On Endogenous Growth: The Implications of Environmental Extenalities, Journal of Environmental Economics and Management 31(2), 240-68.

Futagami, K. and K. Mino, 1995, Public Capital and Patterns of Growth in the Presence of Threshold Externalities, Journal of Economics 61(2), 123-46.

Gaube, T., 2005, Second-Best Pollution Taxation and Environmental Quality, Frontiers of Economic Analysis \& Policy 1(1), Article 1.

Glomm, G. and B. Ravikumar, 1999, Competitive Equilibrium and Public Investment Plans, Journal of Economic Dynamics and Control 23(8), 1207-24.

Goulder, L., 1995, Effects of Carbon Taxes in an Economy with Prior Tax Distortions: An Intertemporal General Equilibrium Analysis, Journal of Environmental Economics and Management 29(3), 271-97.

Gradus, R. and S. Smulders, 1993, The Trade-off between Environmental Care and Long-Term Growth - Pollution in Three Prototype Growth Models, Journal of Economics 58(1), 25-51.

Greiner, A. and H. Hanusch, 1998, Growth and Welfare Effects of Fiscal Policy in an Endogenous Growth Model with Public Investment, International Tax and Public Finance 5(3), 249-61.

Hettich, F., 1998, Growth Effects of a Revenue-neutral Environmental Tax Reform, Journal of Economics 67(3), 287-316.

Jones, L. and R. Manuelli, 1997, The Sources of Growth, Journal of Economic Dynamics and Control 21(1), 75-114.

Jones, L., R. Manuelli, and P. Rossi, 1993, Optimal Taxation in Models of Endogenous Growth, Journal of Political Economy 101(3), 485-517.

Jorgenson, D. and P. Wilcoxen, 1990, Environmental Regulation and U.S. Economic Growth, Rand Journal of Economics 21(2), 314-40.

King, R., C. Plosser, and S. Rebelo, 1988, Production, Growth and Business Cycles, I: The Basic Neoclassical Model, Journal of Monetary Economics 21(2), 195-232.

Lucas, R., 1988, On the Mechanics of Economic Development, Journal of Monetary Economics 22(1), 3-42. 
Metcalf, G. E., 2003, Environmental Levies and Distortionary Taxation: Pigou, Taxation and Pollution, Journal of Public Economics 87(2), 313-22.

Mino, K., 1996, Analysis of a Two-sector Model of Endogenous Growth with Capital Income Taxation, International Economic Review 37(1), 227-51.

Mohtadi, H, 1996, Environment, Growth, and Optimal Policy Design, Journal of Public Economics 63(1), 119-40.

Neher, P. A., 1990, Natural Resource Economics: Conservation and Exploitation, Cambridge University Press, New York.

Nordhaus, W., 1994, Managing the Global Common, the Economics of Climate Change, MIT Press, Cambridge, MA.

Rebelo, S., 1991, Long-run Policy Analysis and Long-run Growth, Journal of Political Economy 99(3), 500-21.

Rebelo, S. and N. Stokey, 1995, Growth Effects of Flat-rate Taxes, Journal of Political Economy 103(3), 519-50.

Smulders, S. and R. Gradus, 1996, Pollution Abatement and Long-term Growth, European Journal of Political Economy 12(3), 505-32.

Tahvonen, O. and J. Kuuluvainen, 1991, Optimal Growth with Renewable Resources and Pollution, European Economic Review 35(3), 650-61.

van Ewijk, C. and S. van Wijnbergen, 1995, Can Abatement Overcome the Conflicts between the Environment and Economic Growth, De Economist 143(2), 197216.

Xepapadeas, A., 1997, Economic Development and Environmental Pollution: Traps and Growth, Structural Change and Economic Dynamics 8(3), 327-50. 